\title{
Corpus
}

Archivos virtuales de la alteridad americana

Vol 6, No 2 | 2016

Julio / Diciembre 2016

\section{Conservar el vacío. Imágenes de la desaparición de los negros en el Archivo General de la Nación}

Sergio Caggiano

\section{(2) OpenEdition}

\section{Journals}

\section{Electronic version}

URL: http://journals.openedition.org/corpusarchivos/1740

DOI: 10.4000/corpusarchivos. 1740

ISSN: 1853-8037

\section{Publisher}

Diego Escolar

\section{Electronic reference}

Sergio Caggiano, « Conservar el vacío. Imágenes de la desaparición de los negros en el Archivo General de la Nación », Corpus [En línea], Vol 6, No 2 | 2016, Publicado el 29 diciembre 2016, consultado el 02 mayo 2019. URL : http://journals.openedition.org/corpusarchivos/1740 ; DOI 10.4000/corpusarchivos.1740

This text was automatically generated on 2 May 2019. 


\title{
Conservar el vacío. Imágenes de la desaparición de los negros en el Archivo General de la Nación
}

\author{
Sergio Caggiano
}

\section{Introducción}

1 Los archivos producen "la sensación de aprehender la realidad por fin (...) Como si la prueba de lo que fue el pasado estuviera por fin allí, definitiva y cercana" (Farge 1989 p. 14 y 18). Esto ha permitido que los archivos nacionales, en tanto tecnologías estatales, sostengan la producción de los Estados mismos (Stoler 2002) y "formas de identificación de la comunidad nacional" (da Silva Catela 2002, p. 217; Gomes da Cunha 2002). Tal sensación de "aprehender la realidad" se duplica en el caso de un archivo de fotografías, pues la fotografía se ha caracterizado desde un comienzo por el efecto de realidad que produce (Barthes 1986; Schaeffer 1990). ${ }^{1}$

2 El Departamento de Documentos Fotográficos (DDF) del Archivo General de la Nación (AGN) contiene uno de los fondos visuales más importantes de Argentina. Actualmente pone a consulta pública alrededor de cuatrocientos mil documentos y constituye una referencia fundamental para investigadores, productores de medios de comunicación, realizadores de films y fotógrafos, funcionarios y empleados de "cultura", autores de materiales didácticos y curadores. Como fuente de imágenes históricas, entonces, juega un papel clave en la imaginación del pasado nacional.

3 Mi trabajo en el DDF se originó en 2008 con la pregunta acerca del vínculo entre su acervo y los modos en que clase, género y raza tomaban forma en las imágenes de circulación pública (álbumes históricos, manuales escolares y sitios de Internet) que analizaba en ese momento (Caggiano 2012). ¿Qué fotografías (de hombres y mujeres, blancos, indígenas, y negros, etc.) eran efectivamente conservadas en el principal archivo nacional? Una vez iniciada la exploración, resultó clave indagar lo propia lógica clasificatoria del archivo: 
¿qué dimensiones de clasificación y división social ordenaban su acervo?, ¿qué compartimentos guardaban sus fotografías?, ¿qué ligazones y desconexiones podría rastrearse entre ellas?

4 Recupero aquí algunas de estas inquietudes generales, concentrándome en las fotografías, fichas y cajas relativas a la presencia negra en Argentina: ¿qué imágenes de la negritud en Argentina preserva el AGN?, ¿qué anclajes semánticos proponen los textos verbales que acompañan las imágenes (catálogos, fichas y escrituras en el reverso de las fotos)?, ¿qué juegos de sentido se configuran entre las imágenes y los sistemas y categorías de clasificación que las organizan? ¿Persiste visualmente el mito fundante de la nación argentina moderna blanca europea $\mathrm{y}$, como una de sus partes componentes, la invisibilización de los negros (Goldberg 2000; Frigerio 2008)? ¿Pueden advertirse quiebres respecto de esta narrativa maestra?

5 Analizo dos aspectos que caracterizan el modo en que el DDF preserva las imágenes de negros en Argentina, e intento llamar la atención precisamente sobre la coexistencia de ambos, en la medida en que aparentemente divergen en su orientación. De un lado, una renovación en el modo de nombrar a este sector de la población, abandonando la categoría "negros" para dar lugar a "afroamericanos", más acorde a los usos extendidos internacionalmente en las últimas décadas. Del otro, una operación sutil que insiste en la invisibilización de los negros en Argentina, y que consiste en la mostración de su desaparición y de su ausencia.

\section{Correcciones políticas}

6 Pautas consuetudinarias y reglas de funcionamiento como la de guardar el orden de procedencia, que implica no modificar la organización de un archivo cuando es recibido, determinan una gran estabilidad en el ordenamiento del acervo a lo largo del tiempo. La mayoría de las entradas del Índice Temático son antiguas y parecen proceder de la creación misma del Archivo Gráfico, que se convertiría luego en el actual DDF, o incluso del trabajo de organización previo a su inauguración, en la segunda mitad de la década de $1930 .^{2}$

7 No obstante, la fijeza de la organización de los materiales no es absoluta. Cuando uno se dirige, siguiendo la lógica propuesta por el archivo, desde el índice al fichero, ${ }^{3}$ puede hallar pequeñas variaciones, la más común de las cuales es que el nombre de un tema o subtema ya no contenga fotografías y una anotación reenvíe a otro tema o subtema ("Ver «X»"). Ha habido reagrupamientos $\mathrm{y}$, en diferentes momentos, se ha dispuesto que una ficha reconduzca a otra. Se intenta, según señalan en el DDF, que los nombres de temas y subtemas que devienen inútiles o equívocos por el envejecimiento del lenguaje no generen a los usuarios más inconvenientes que ayuda.

8 Una situación semejante se verifica en torno a la indexación y descripción de cada fotografía en particular. Si bien la tendencia ante las eventuales dudas en las referencias de las imágenes es a no innovar, el cuerpo de las fotos registra el paso del tiempo y constata una dinámica de pequeñas enmiendas y agregados que dan cuenta de mutaciones, presumiblemente lentas pero constantes. El reverso de las fotos es el espacio privilegiado para este registro y esta constatación.

9 En este marco de continuidades y pequeños cambios, en los que el archivo muestra ser un espacio lleno de vida (Jelin 2002), recientemente se dio uno de gran relevancia. Fue 
eliminada del Índice Temático la entrada Negros $\mathrm{y}$, en su reemplazo, apareció Afroamericanos, que mantuvo las divisiones internas anteriores. El índice vigente en la actualidad es de 2011, pero este reemplazo puntual es más reciente, de enero de 2016 . Entre los setenta temas y los mil trescientos subtemas del índice son muy escasas las categorías sociales, es decir, los nombres de grupos o sectores sociales. Dicha escasez vuelve más relevantes las efectivamente presentes, que entre los temas son apenas dos: "afroamericanos" y "aborígenes". ${ }^{4}$

Las categorías sociales son el resultado de los procesos de clasificación social y el sostén sobre el que ésta clasificación se apoya (Douglas y Hull 1992; Ortner 2006; Bourdieu 1982) y son fundamentales "porque sus límites hacen un crucial trabajo organizacional" (Tilly 2000 , p. 20). La clasificación social y las categorías oficialmente adoptadas por los Estados son incorporadas a la ley y a los aparatos administrativos, disponen asignaciones de recursos, distribuciones de responsabilidades y de garantías y organizan las estadísticas sociales. Como parte de los archivos nacionales y de otras instituciones de preservación y difusión, afectan directamente la formación de los imaginarios sociales (Baczko 1999). La mera selección de categorías, entonces, parcial por definición, lleva a que nos preguntemos cuál es el telón de fondo "no negro" y "no indio" (o no "afroamericano" y "no aborigen") sobre el que pueden recortarse tales "particularidades". Su sola distinción y definición postula una blanquitud sobreentendida para el resto del acervo que, contra estas figuras marcadas, parece presentarse como la norma.

11 Simultáneamente, quizás como parte del mismo proceso de revisión y corrección, se ha dado la reubicación de algunas fotografías que hasta 2010 podían hallarse en el tema Negros y hoy no forman parte de Afroamericanos. Una de las más significativas de estas reubicaciones ha hecho que ya no se encuentre allí la fotografía de los "Negros porteños", "populares candomberos", que, en rigor, retrataba a jóvenes blancos con sus caras tiznadas para el carnaval. La enmienda, no obstante, parece haber quedado incompleta, en la medida en que permanecen como parte del nuevo tema imágenes como la de los "negros Congos" de la imagen 1, entre quienes también vemos personas blancas pintadas de negro. 


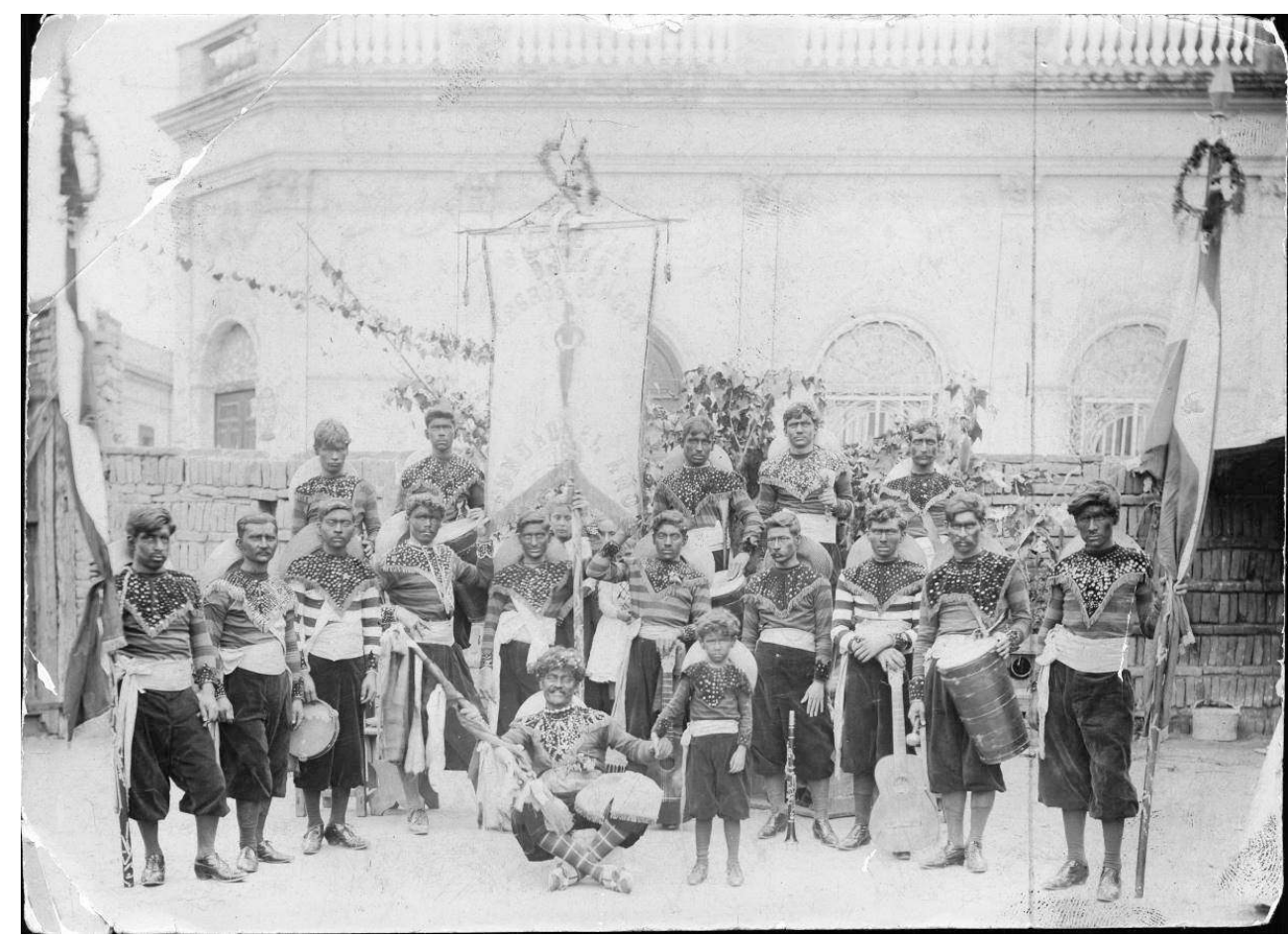

Imagen 1. "Sociedad de los negros Congos" (1891). ${ }^{5}$ Archivo General de la Nación (AGN), Dpto. Doc. Fotográficos (DDF).

La sustitución de Negros por Afroamericanos renueva los criterios de diferenciación social que habitan los catálogos del archivo y procura sortear los efectos discriminatorios que pudiera trasuntar la categoría reemplazada. El puntapié inicial de esta innovación lo dio una investigadora que presentó una nota en la que manifestaba su disconformidad con aquella categoría. Más allá de las precauciones que indica la regla de guardar el orden de procedencia, se actuó como en los casos en que alguien certifica y prueba la incorrección de un dato en los documentos y, en consecuencia, se accedió a cambiar la categoría. En última instancia, lo que se procuró fue "no herir susceptibilidades" y adecuar mejor las categorías y denominaciones al léxico contemporáneo. ${ }^{6}$ Con conciencia del peso que tiene la elección de nombres como categorías ordenadoras del AGN, y haciendo lugar a sugerencias externas, se llevó a cabo una corrección (que es) política.

\section{"Negros" y "afroamericanos" no son lo mismo pero, lo mismo, no son}

13 Más allá de estos cambios, la característica principal del tema se mantiene intacta. De la misma manera que sucedía en Negros, en Afroamericanos hay muy pocas fotografías y, lo que es todavía más significativo, de las pocas existentes, casi ninguna es de personas negras. En el puñado de fotos reunidas en el tema, pueden distinguirse tres grupos.

Por un lado, están las imágenes que evocan la presencia negra en el pasado del actual territorio argentino. Entre ellas, copias de algunas de las clásicas litografías de Gregorio Ibarra, probablemente provenientes de su Serie Chica, de 1839, que muestran al "Vendedor de velas", el "Vendedor de escobas" o la "Lavandera" de la época colonial, la foto de una escultura, presentada como "monumento a la etnia negra", y reproducciones de diseños interiores de buques dedicados al tráfico de esclavos (imágenes 2 y 3 ). 


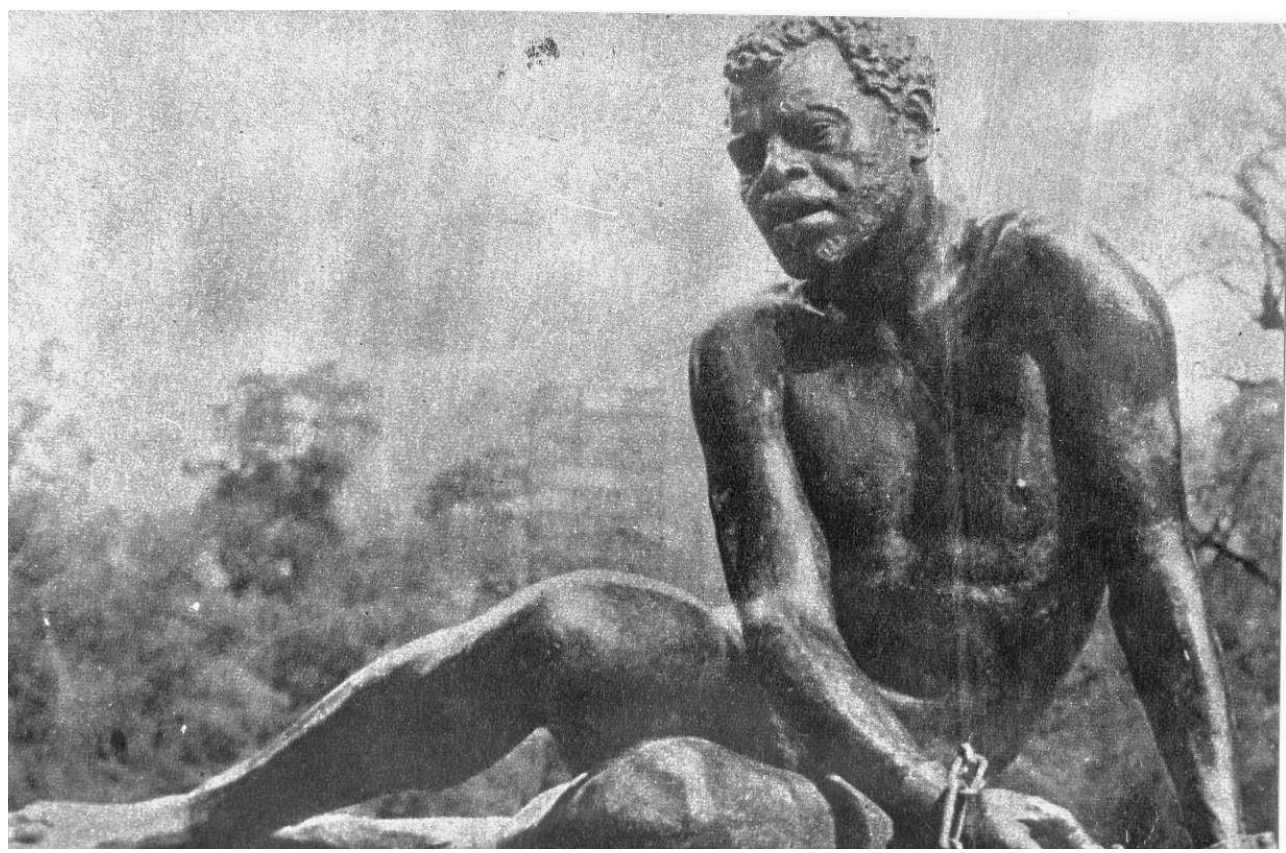

Imagen 2. "Monumento a la etnia negra" (s/f). AGN, DDF.

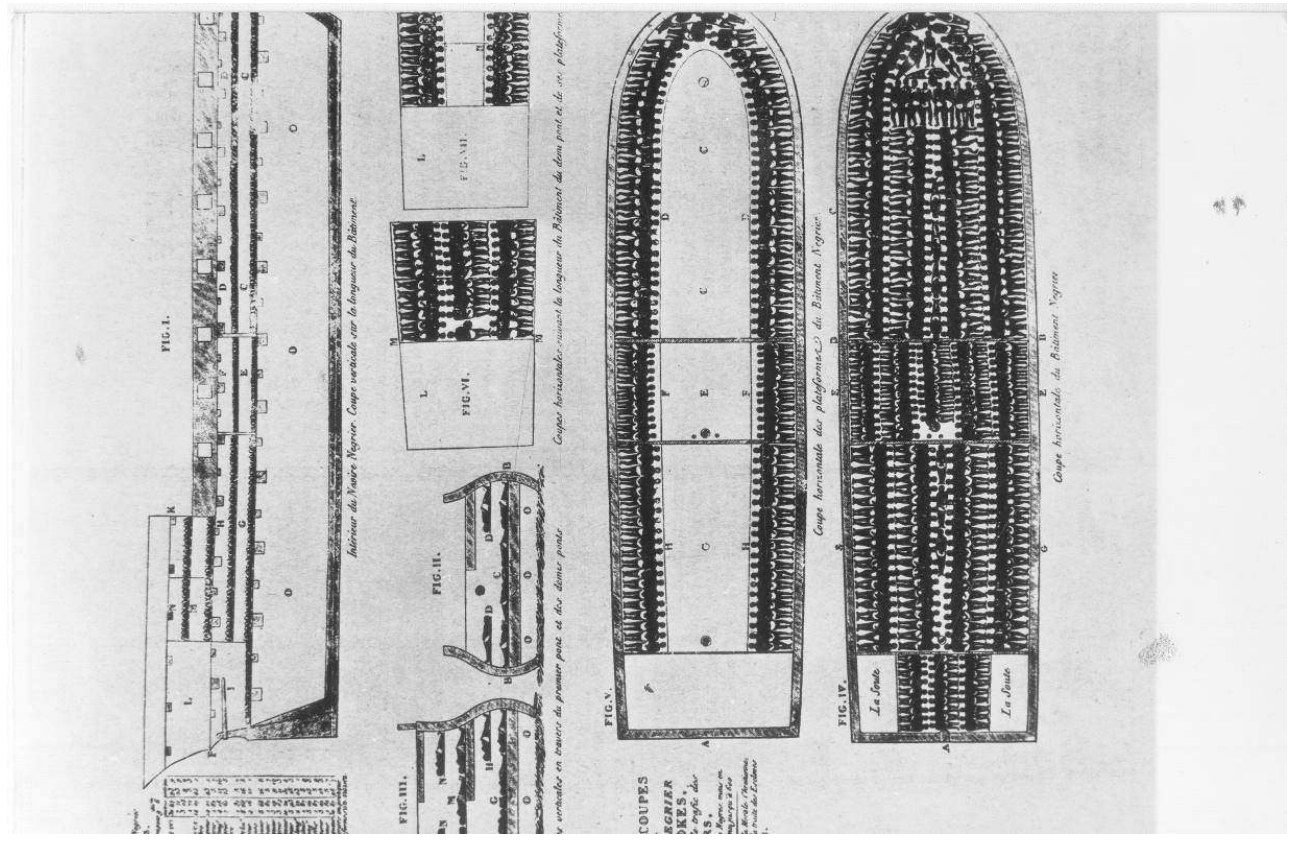

Imagen 3. "Diseño del Buque Brookes" (s/f). AGN, DDF.

Por otro lado, encontramos las pocas imágenes de personas, las cuales, más allá de esta peculiaridad, comparten el principal rasgo del grupo anterior: su cariz evocatorio. Una fotografía de finales de la década del treinta presenta a un grupo de hombres y mujeres morenos/as con ropas e instrumentos musicales de "candomberos", con el rótulo "Trajes típicos" en el reverso y un recorte de prensa pegado que rescata, como "cuadro costumbrista", este baile "alrededor de la clásica fogata". La reproducción parcial de una publicación impresa, a su vez, deja ver a "dos morenas representantes del carnaval antiguo", con amplios vestidos y pañuelos en sus cabezas. Completan este segundo grupo los retratos de inicios del siglo XX de dos "tipos populares", según las palabras en el 
reverso de una de las fotos: José de Urquiza, presentado como "el último mazamorrero", y Raúl Grigeras, quien fuera mejor conocido como "El Negro Raúl” (imágenes 4 y 5).

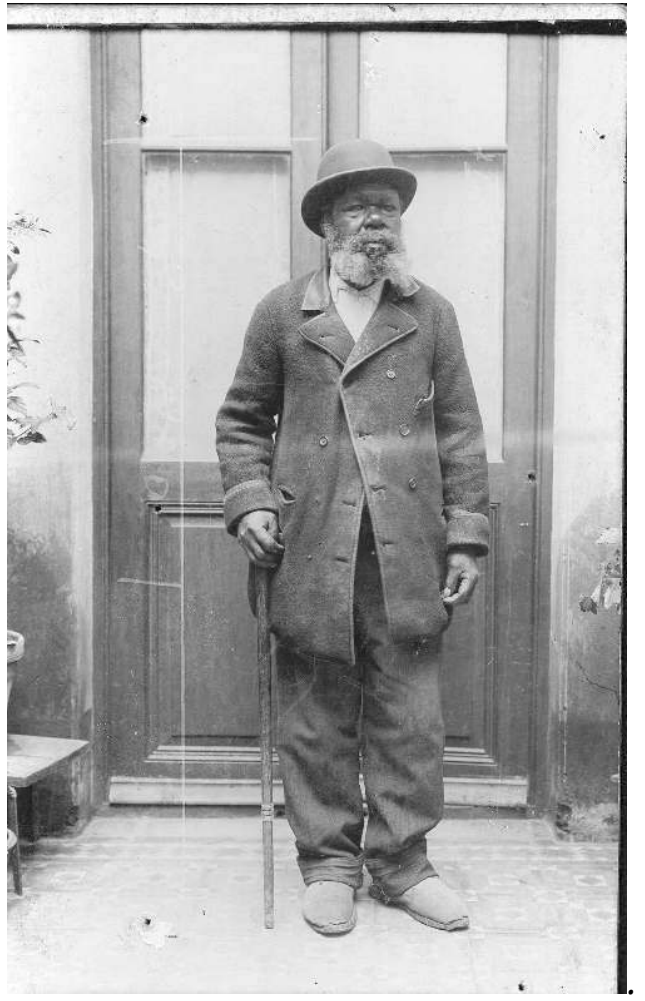

Imagen 4. "El último mazamorrero" (¿1900?). AGN, DDF

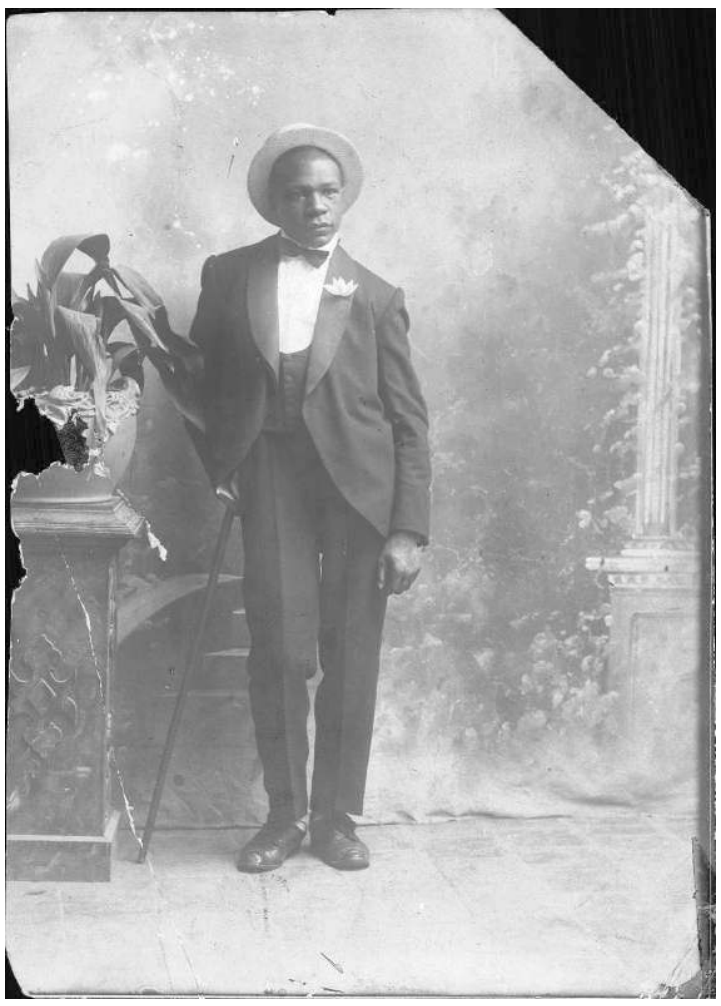

Imagen 5. "El Negro Raúl" (primera o segunda década del s. XX). AGN, DDF. 
El tercer grupo de fotografías pone en imagen la ausencia misma de las personas negras. Podemos ver el dibujo de la "Plaza de Montserrat en 1844, barrio habitado por negros", una serie de instrumentos musicales "de negros candomberos", sin personas a la vista, la “mesa presidencial de la Sociedad de Negros «Nación Benguela»", de fines del siglo XIX, sin nadie sentado allí $\mathrm{y}$, sin abanderados, banderas y estandartes de "Sociedades de Negros"; por último, el edificio donde funcionara un candombe al que habría asistido con frecuencia Manuelita Rosas, en una calle que se ve virtualmente desierta del barrio de Montserrat (ver imágenes 6 y 7).

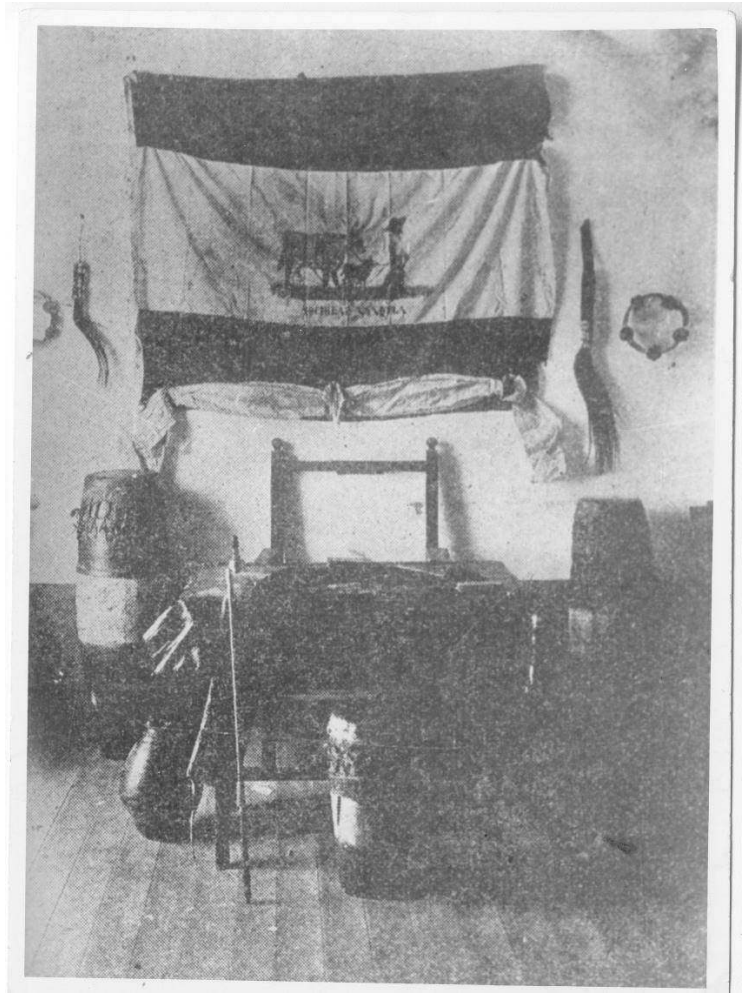

Imagen 6. "Mesa presidencial de la Sociedad de Negros Nación Benguela" (fines del s. XIX). AGN, DDF. 


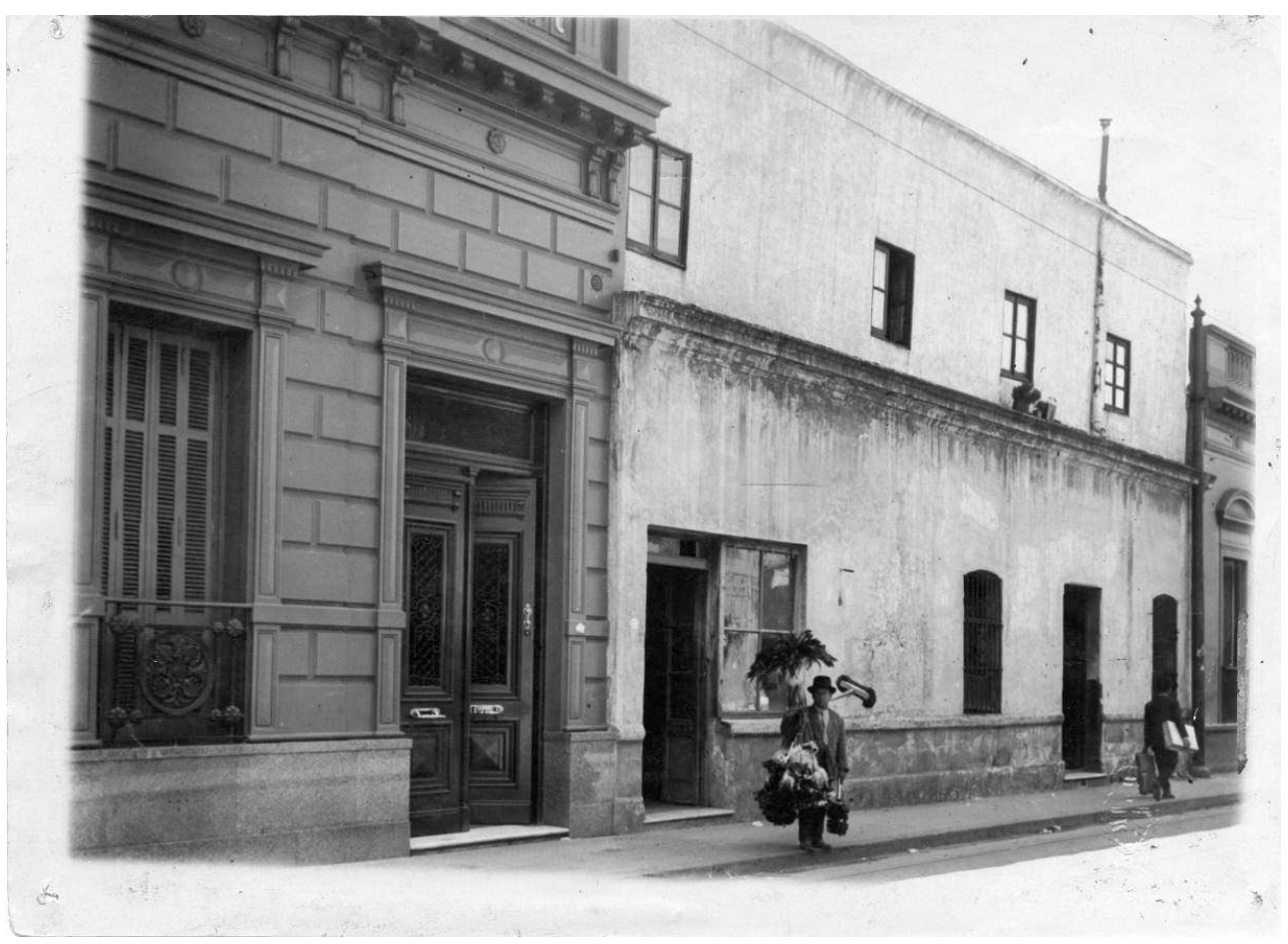

Imagen 7. "Casa Candombe de Grigera" (s/f). AGN, DDF. distinción, pero una íntima vinculación emparenta a todas las fotografías: la mostración de la desaparición y de la ausencia. La operación se concreta con el encierro de la presencia negra en un pasado lejano, mecanismo que el archivo comparte con álbumes históricos de gran circulación y manuales escolares, por ejemplo (Caggiano 2012). Esta remisión a un pasado muchas veces anterior al período histórico que recoge el DDF se aprecia en los dibujos de la Colonia y de los buques negreros y en las fotografías de personas que están allí como representantes de bailes y carnavales "típicos", "clásicos" o "antiguos", como últimos exponentes de algún oficio en desuso o, en el caso de Grigeras, como el protagonista de un "cuento racial" argentino que narra precisamente la “«desaparición» de la negritud y de los mismos afroargentinos a partir del comienzo del siglo XX" (Alberto 2016, p. 137).

En las fotos de espacios, enseres y emblemas hay, además, un modo específico en que el archivo concreta la mostración de la desaparición y la ausencia. Las calles y edificios vacíos ponen en escena la pérdida de una presencia que el texto verbal constata (para el pasado) en el reverso o en la ficha de la fotografía. Son espacios des-ocupados. Las banderas y los instrumentos musicales, a su vez, sin nadie que haga uso de ellos, revelan una quietud redoblada. Están expuestos en calidad de reliquias, vestigios de una vida pretérita.

pequeño espacio del fichero ocupado por el tema Afroamericanos es significativo precisamente por su pequeñez, así como por su virtual vacuidad, especialmente en lo que hace a fotografías de personas negras argentinas que puedan testimoniar o sugerir algún tipo de conexión con el presente. En su pequeñez el tema consigue ser elocuente. Su escasez parece contrastar con la selección misma del nombre para designar un tema del índice, pero, en verdad, no hay contraste alguno. La aparente contradicción de que exista un tema casi vacío produce, antes bien, el apuntalamiento de un trazo del sentido común 
local, la reiteración y confirmación de que en Argentina "no hay negros" o, con mayor precisión, "ya no hay negros". El hecho de que la vacuidad motive un tema del índice refleja un gesto central de las narrativas oficiales del siglo XX, que con fórmulas míticas como "en Argentina no hay negros" o "en Argentina no hay indios", lejos de volver inexistentes a "los negros" y a "los indios", los volvían una existencia negada (Caggiano 2012). No es que no haya lugar para los negros o afroamericanos en el departamento de fotografías del AGN. Hay un lugar casi vacío que hace aparecer la desaparición: "esto que ve usted aquí es un nombre; no tiene imagen". O mejor, como en una paráfrasis de Magritte (y de Foucault 1999), el archivo dice/muestra: "esto no es una presencia negra".

La operación que le toca llevar adelante al tema Afroamericanos se hace más patente cuando uno bucea en otras zonas del DDF. En otro trabajo pude producir, concentrando la búsqueda apenas en el sector del archivo reservado a imágenes del ejército, un pequeño ensayo visual que da cuenta de la presencia negra a lo largo de la historia moderna de esa institución, con imágenes como la 8 y la 9.

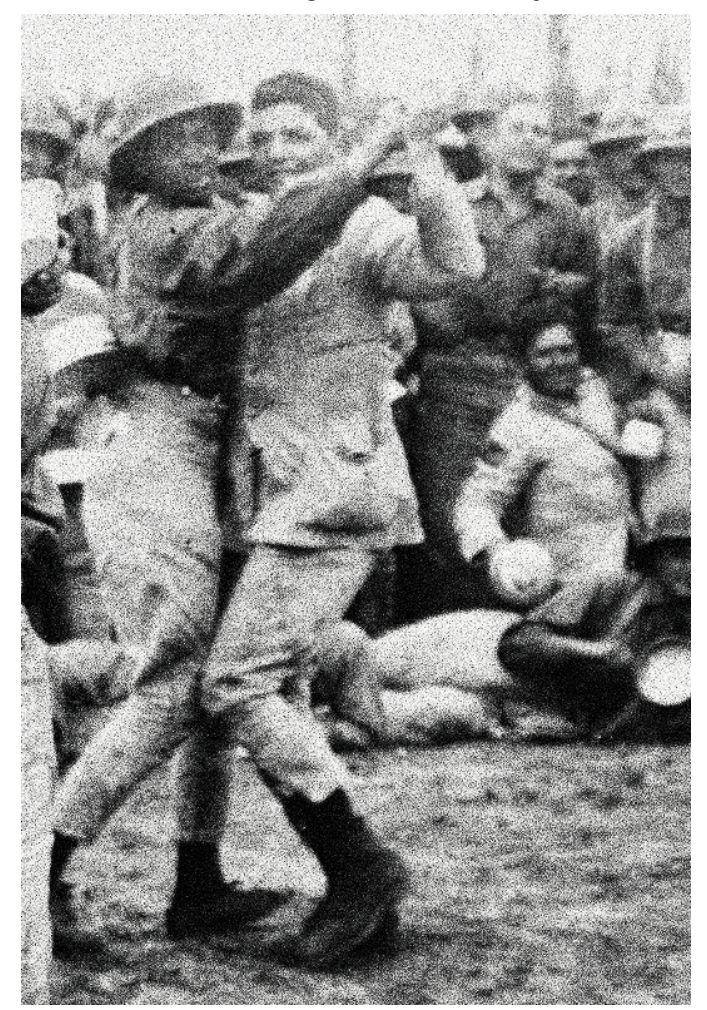

Imagen 8. "Después de las fatigas de los pesados ejercicios..." (Mendoza, 1927). AGN, DDF 


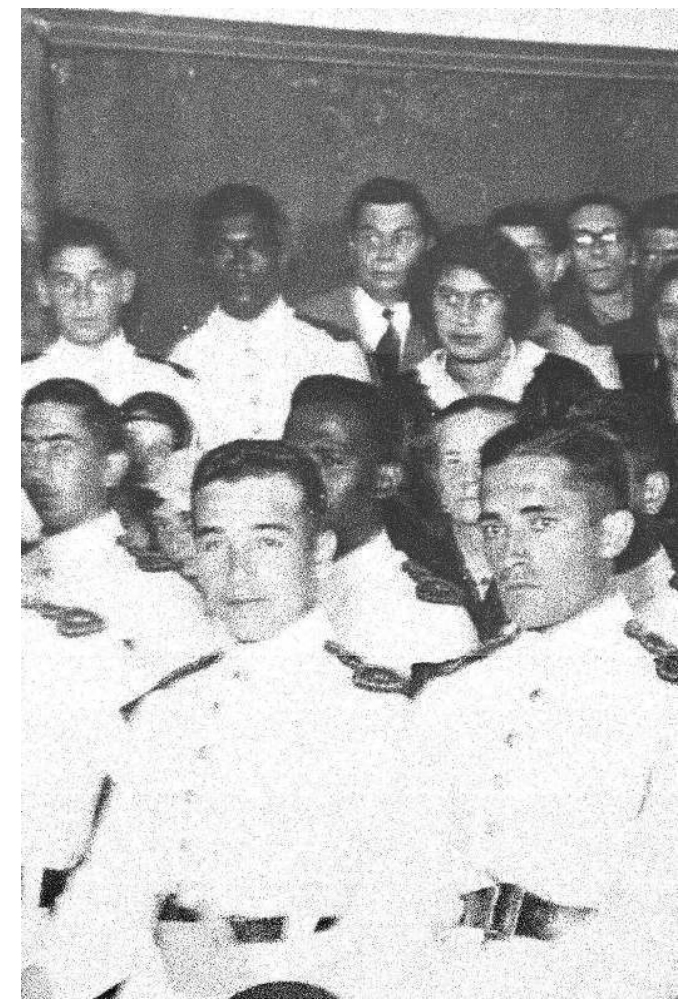

Imagen 9. "Una pequeña fiesta en el Colegio Militar” (fragmento, ¿1930?). AGN, DDF.

La buena disposición y esmero de un empleado del DDF también pueden generar pistas de investigación. Recientemente digitalizados, y aún en proceso de catalogación, se encuentran disponibles en el departamento los folios de los Álbumes de Contactos Witcomb, ${ }^{8}$ con decenas de miles de retratos producidos entre 1888 y 1904 . A pesar de que este conjunto de fotografías recorta una porción muy pequeña de la población, puesto que el retrato en esa época era accesible solo a personas de buena posición económica, las personas negras también están allí (ver imágenes 10 y 11). En este punto podría comenzar un análisis de estas imágenes que, incluso sin contar con datos precisos que les correspondan, plantean interesantes retos. Porque entre los retratados hay quienes podrían haber recibido el financiamiento de la toma por parte de terceros, como las mujeres encargadas del cuidado de niños blancos o los soldados del ejército, pero también personas negras cuyo ascenso social les habría permitido perpetuar su propia imagen. $Y$ porque estas fotos permiten apreciar que la negritud no es nunca, como la blanquitud, simplemente un color de piel. $\mathrm{O}$ en todo caso, es un color de piel tan variable como lo es la apariencia de clase. 


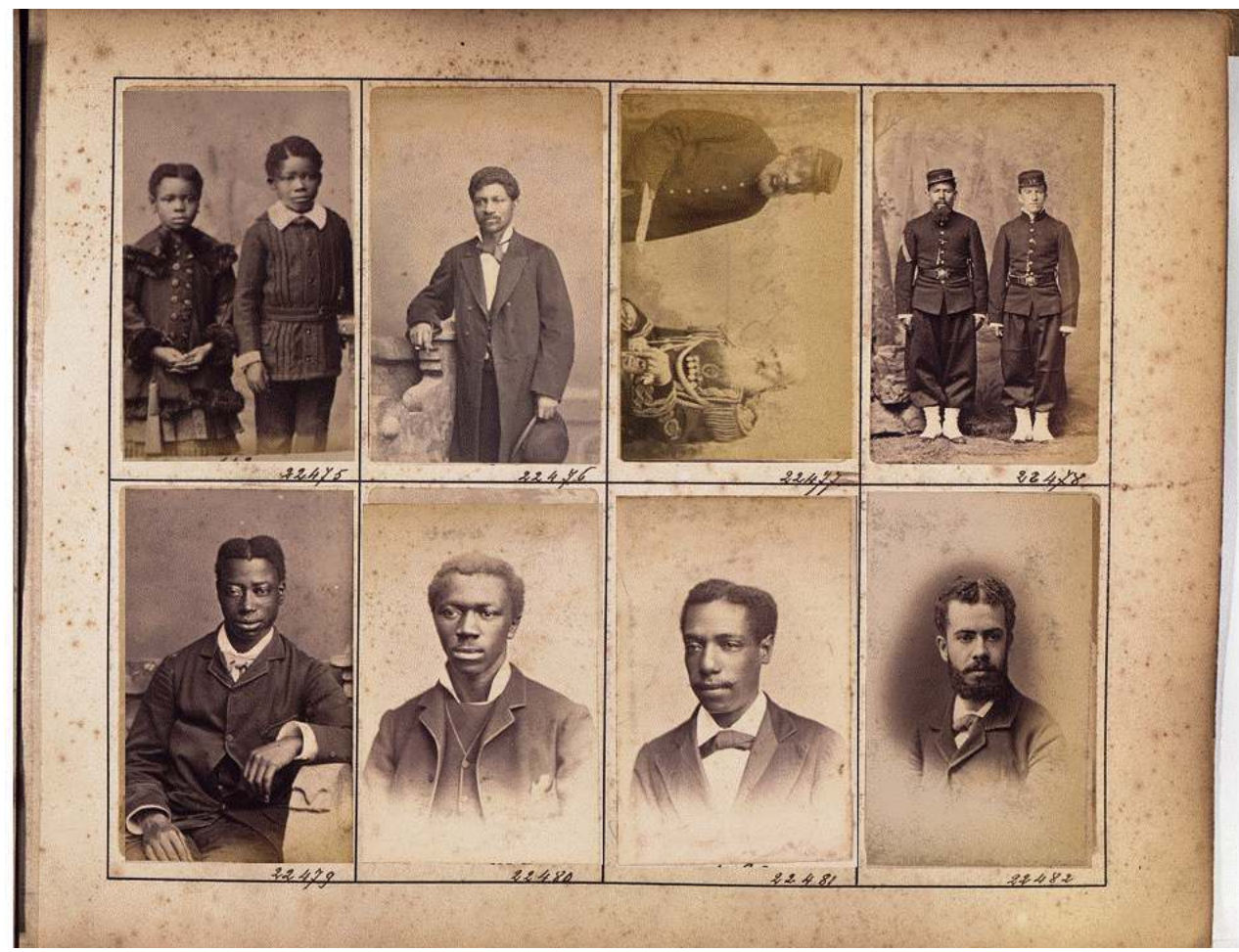

Imagen 10. Álbumes de contactos Witcomb. AGN, DDF. ${ }^{9}$

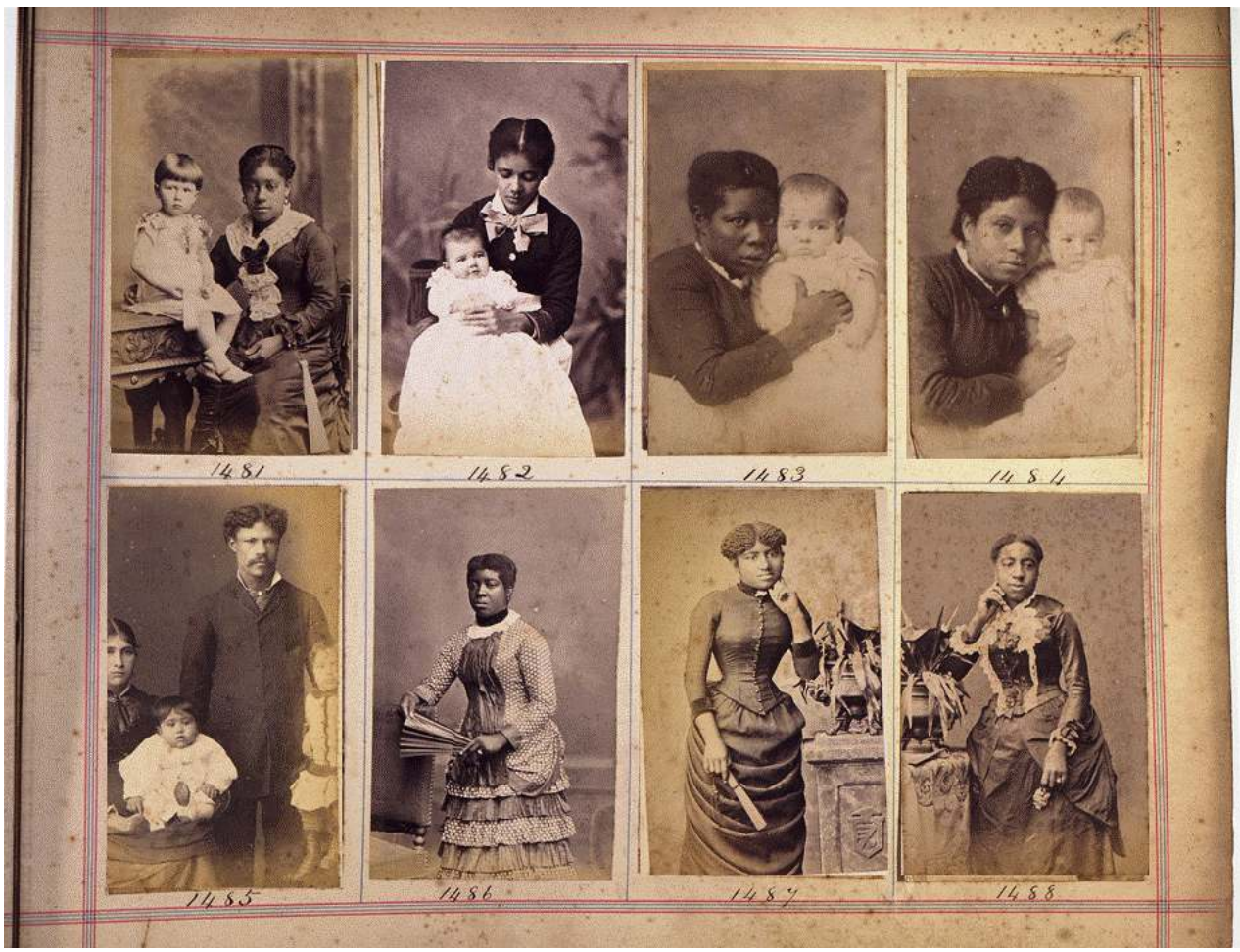

Imagen 11. Álbumes de contactos Witcomb. AGN, DDF.

Ahora bien, más allá de estas exploraciones y de lo mucho que queda por hacer al respecto, el punto es que las personas negras casi no están en el tema Afroamericanos, pero esto no significa que no estén en el archivo. Están y se ven, aunque no sean calificadas y clasificadas como Afroamericanas. Como si la inexistencia en aquella parte 
del fichero pudiera encontrar una contestación dispersa entre otras cajas y bajo otros rótulos.

\section{Conclusiones e inquietudes}

23 El espacio vivo del archivo se tensiona entre cambios y continuidades. El recurso a la categoría "afroamericanos" para nombrar un sector del fichero pone en acto una búsqueda institucional dirigida a corregir los que se consideran sesgos inapropiados en la nomenclatura anterior. La carga negativa que en el DDF consideran que tendría el término "negros" busca ser evitada atendiendo a los modos contemporáneos en que distintos actores sociales (activistas, investigadores, miembros de ONGs y de otras dependencias del Estado) se refieren a este sector de la población en los últimos años, tanto en Argentina como en otras latitudes y a diferentes escalas.

No obstante, la sustitución de la categoría "negros" por "afroamericanos" y la valiosa inquietud que la motiva conviven con la mostración de la desaparición y de la ausencia, operación que se entreteje con las líneas maestras de un sentido común largamente alimentado durante al menos un siglo en Argentina, que ha insistido en reenviar la presencia negra al pasado de la nación y en borrarla de su presente. Otero analizó el papel de la armazón censal definida por el sistema estadístico en la "desaparición estadística" de indígenas y negros entre finales del siglo XIX y comienzos del XX (Otero 1998; Frigerio 2006). ${ }^{10}$ Otros autores estudiaron más tarde maniobras narrativas -"genocidio discursivo" (Solomianski 2003) o "entierro retorico" (Alberto 2016)- que configuraron una mirada "filtrada por la negación" (Solomianski 2003, p. 23), que vino a complementar en el plano simbólico los fenómenos políticos, sanitarios y militares que produjeron la reducción demográfica de la población afroargentina. A la desaparición estadística, el genocidio discursivo y el entierro retórico, el departamento de fotografías del AGN añade la inhumación visual que sus mecanismos específicos producen.

Sugiero que la importancia de esta doble tendencia simultánea no reside solamente en el peso de una dependencia estatal como el AGN, que es ya suficiente, sino en que podría hipotetizarse su funcionamiento en otros ámbitos de la vida social local. La reivindicación y visibilización ${ }^{11}$ contemporáneas de la herencia y actualidad negra, afrodescendiente o afroargentina convivirían con modalidades más o menos ingeniosas de negación de aquellas, en ocasiones emergiendo ambas tendencias, como en el AGN, desde el mismo lugar de enunciación.

26 La tensa coexistencia de estas dos orientaciones nos recuerda, además, que los sistemas y categorías de clasificación no se sustituyen absoluta y definitivamente, no se abandonan unos que quedan sepultados para siempre y se abraza otros que, surgidos de la nada, pasan a funcionar sin vinculación alguna con los anteriores. Hay variadas superposiciones y entrelazamientos. La proliferación contemporánea de términos identitarios (afroamericanos, afrolatinoamericanos, afroargentinos, afrodescendientes, negros, entre otros) y las disputas alrededor de ellos dan cuenta de un momento de particular riqueza al respecto. En todo caso, son personas (diferentes y desiguales) las que tratan con dichos sistemas y categorías, es decir, quienes los usan y transforman.

Y el panorama se complejiza aun más si consideramos el funcionamiento específico y combinado de palabras e imágenes. En la mínima mención hecha de las categorías censales pudo percibirse una historia de transformaciones y cambios. Pero sabemos que, 
mientras en este y otros ámbitos institucionales el criterio racial de clasificación social era abandonado, categorías como "negro" o "indio" eran usadas en intercambios cotidianos, cantadas en canciones populares o espetadas desde una tribuna política o desde una futbolística. O sobrevivían "al menos" para negar que en Argentina existieran quienes hubieran podido incluirse en alguna de ellas. Además, a propósito de la relación entre categorías (verbales) y estructuración de la mirada, cuando el Estado nacional, por ejemplo, dejó de utilizar las categorías socioraciales, ¿la gente dejó inmediatamente de ver negros y pardos?, y si en los tiempos que corren se estabilizara la inclusión administrativa de la afrodescendencia, ¿pasaríamos a ver rápidamente afrodescendientes?, ¿habría un modo preciso de definir qué sería "ver afrodescendientes"?

Esto último conduce a un problema primero: ¿cómo mostrar la presencia negra en Argentina? Desde el proceso de construcción del Estado-nación moderno se configuró una narrativa oficial y hegemónica "de blanquitud y europeidad, «libre» del mestizaje presente en otros países de la región" (Guzmán, Geler y Frigerio 2016, p. 11). Un siglo después, las organizaciones de afroargentinos -descendientes de esclavos en el Río de La Plata, descendientes de migrantes africanos de finales del siglo XIX o migrantes recientes- impulsaron una re-visión de la presencia negra en la historia argentina, y lograron poner el tema en la agenda política y cultural, nacional y transnacional.

El siglo XX, entonces, constituye un período crítico para la visibilización de las personas negras en Argentina: "media entre su «desaparición» a fines del siglo XIX y su «reaparición» o re-visibilización a comienzos del siglo XXI" (Frigerio 2008, p. 1). Para los activistas culturales y las organizaciones de afroargentinos que han sumado esfuerzos en esta empresa de visibilización y visualización, el hiato entre las imágenes del pasado lejano y las del presente plantea un desafío. Entre ellas se tiende un manto de invisibilidad que es invisible él mismo. Pero la respuesta ante este hiato no es para nada simple.

Como demostró Geler, la "comunidad afroporteña" no pudo sobrevivir como tal tras un complejo proceso en que las distancias sociales y divergencias internas de dicha comunidad, la convergencia entre sus reclamos y los de otros grupos y, especialmente, las alianzas de miembros dirigentes de la comunidad con grupos de poder aportaron al establecimiento de la blanquitud argentina, entendida como civilizada, urbana y europea. Las alianzas de intelectuales afroporteños con grupos hegemónicos condujeron por el camino de la "regeneración" de los negros, que implicaba civilización y ocultamiento del pasado, y llevaron a evitar el combate contra el "mandato de homogeneidad blancaeuropea" en clave de visibilización racial. La homogeneidad nacional resultó, entonces, de una construcción consensuada. "La indiferenciación -o desmarcación- que ofrecían categorías como «vulgo» o incluso como «obrero», o la de «ciudadano-soberano» (...) eran impuestas pero también retomadas, usufructuadas y defendidas por los afroporteños" (Geler 2010, p. 386).

31 El proceso de exclusión e inclusión, negación y negociación, invisibilización y blanqueamiento durante un siglo resultó de un intrincado juego de enfrentamientos y alianzas con diversos participantes a lo largo de la historia, que implicó categorías, clasificaciones e imágenes que condicionan los modos cómo experimentamos qué es cada quién y cómo nos vemos unos a otros. Señalar el manto de invisibilidad y reclamar que se lo quite sería apenas un primer paso. Exhumar y poner a circular fotografías de esas largas décadas no resolvería el problema, lo plantearía, porque el desafío comienza allí: 
¿qué es lo que mostrarían esas imágenes?, ¿a quiénes mostrarían? Para el caso concreto del DDF, ¿se trataría de llenar de imágenes el sector de Afroamericanos?, ¿qué implica mantener categorías "particulares" como "aborígenes" o "afroamericanos" como temas del índice?, ¿qué conllevaría abandonarlas?, ¿tendría sentido crear el tema Blancos, por ejemplo?...

Algunas de las preguntas más generales formuladas en otro lugar (Caggiano 2015) para los indígenas, que deben desandar un proceso hegemónico de negación y silenciamiento específico pero con muchos puntos en común, valen para los afroargentinos. ¿Cómo realizar una genealogía visual que reponga imágenes de esta historia sin pretender reponer una continuidad o un encadenamiento sin sobresaltos? ¿Con qué imágenes mostrar las continuidades y las discontinuidades? ¿Qué imágenes pueden unir el lejano pasado negro y la actualidad afrodescendiente?, ¿se trataría, como en un retorno de la fisiognomía, de fijar la atención en los cuerpos?, ¿en cuáles rasgos? ¿Cómo rectificar el hiato que salta de la presunta desaparición a la reaparición?, ¿cómo reponer visualmente la existencia por debajo de la negación, mostrando a la vez la negación?, ¿qué imágenes podrían mostrar el hiato mismo, los cortes y los olvidos?

\section{BIBLIOGRAPHY}

Alberto, P. (2016). “Títere roto": vidas (posibles) y vidas póstumas del “Negro Raúl”. En F. Guzmán, L. Geler y A. Frigerio (Eds.), Cartografías afrolatinoamericanas. Perspectivas situadas desde la Argentina. Buenos Aires: Biblos.

Baczko, B. (1999). Los imaginarios sociales: memorias y esperanzas colectivas. Buenos Aires: Nueva Visión.

Barthes, R. (1986). Lo obvio y lo obtuso. Imágenes, gestos, voces. Barcelona: Paidós.

Bourdieu, P. (1982). Ce que parler veut dire. L'économie des échanges linguistiques. París: Fayard.

Caggiano, S. (2012). El sentido común visual. Disputas en torno a género, "raza" y clase. Miño y Dávila editores: Buenos Aires.

Caggiano, S. (2015). Imaginarios racializados y clasificación social: retos para el análisis cultural (y pistas para evitar una deriva decolonial esencialista). Cuadernos Inter.c.a.mbio sobre Centroamérica y el Caribe, Vol. 12 (2), 157-188.

Da Silva Catela, L. (2002). El mundo de los archivos. En L. da Silva Catela, y E. Jelin (Comps.), Los archivos de la represión: Documentos, memoria y verdad. Madrid: Siglo XXI.

Derrida, J. (1997). Mal de Archivo. Una impresión freudiana. Madrid: Editorial Trotta.

Douglas, M. y Hull, D. 1992. Introduction. En M. Douglas y D. Hull (Eds.), How Classification Works. Nelson Goodman among the Social Sciences. Edinburgh: Edinburgh University Press.

Farge, A. (1989). Le gôut de l'archive. Paris: Éditions du Seuil.

Foucault, M. (1991). La Arqueología del Saber. México: Siglo XXI.

Foucault, M. (1999). Esto no es una pipa. Ensayo sobre Magritte. Barcelona: Anagrama. 
Frigerio, A. (2006). “Negros” y “Blancos” en Buenos Aires: Repensando nuestras categorías raciales. Temas de Patrimonio Cultural, Comisión para la Preservación del Patrimonio Histórico Cultural de la Ciudad de Buenos Aires, Núm. 16, 77-98.

Frigerio, A. (2008). De la "desaparición" de los negros a la "reaparición" de los afrodescendientes: Comprendiendo la política de las identidades negras, las clasificaciones raciales y de su estudio en la Argentina". En G. Lechini (Comp.), Los estudios Afroamericanos y Africanos en América Latina: Herencia, presencia y visiones del otro. Buenos Aires y Córdoba: CLACSO y CEA. (versión mimeo.)

Geler, L. (2010). Andares negros, caminos blancos. Afroporteños, Estado y Nación Argentina a fines del siglo XIX. Rosario: TEIAA - Prohistoria ediciones.

Goldberg, M. (2000). Las afroargentinas (1750-1880). En F. Gil Lozano, V. S. Pita y M. G. Ini (Dirs.), Historia de las mujeres en la Argentina, Tomo 1. Buenos Aires: Taurus.

Gomes da Cunha, O. (2002). Intenção e Gesto: pessoa, cor e a produção cotidiana da (in)diferença no Rio de Janeiro, 1927-1942. Río de Janeiro: Arquivo Nacional.

Guzmán, F., Geler, L. y Frigerio, A. (2016). Presentación. Balance y contribuciones. En F. Guzmán, L. Geler y A. Frigerio (Eds.), Cartografías afrolatinoamericanas. Perspectivas situadas desde la Argentina. Buenos Aires: Biblos.

Jelin, E. (2002). Introducción. Gestión política, gestión administrativa y gestión histórica: ocultamientos y descubrimientos de los archivos de la represión. En L. da Silva Catela, y E. Jelin (Comps.), Los archivos de la represión: Documentos, memoria y verdad. Madrid: Siglo XXI.

Ortner, S. (2006). Anthropology and Social Theory. Culture, power, and the acting subject. Durham and London: Duke University Press.

Otero, H. (1998). Estadística censal y construcción de la nación. El caso argentino, 1869-1914. Boletín del Instituto de Historia Argentina y Americana “Dr. Emilio Ravignani”, 3ra. Serie (16 y 17), 123-149.

Richards, T. (1993). The Imperial Archive: Knowledge and the Fantasy of Empire. London: Verso. Schaeffer, J.-M. (1990). La imagen precaria. Del dispositivo fotográfico. Madrid: Cátedra. Sekula, A. (1992). The Body and the Archive. En Bolton, Richard (Ed.), The Contest of Meaning: Critical Histories of Photography. Massachussets: The MIT Press.

Solomianski, A. (2003). Identidades secretas: la negritud argentina. Rosario: Beatriz Viterbo Editora.

Stoler, A. L. (2002). Colonial Archives and the Arts of Governance. Archival Science: International Journal on Recorded Information, 2(2), 87-109.

Tilly, C. (2000). La desigualdad persistente. Buenos Aires: Manantial.

\section{NOTES}

1. Sobre las relaciones de poder de las que el archivo participa, Foucault (1991), Richards (1993) y Derrida (1997), y sobre archivos y fotografía, Sekula (1989).

2. El Archivo Gráfico de la Nación fue creado en 1939 con el objetivo de tomar a su cargo documentos fotográficos y fílmicos. En 1957 fue absorbido por el AGN y pasó a formar parte de él como Departamento Imagen y Sonido. En 1992 el acervo documental de Imagen y Sonido se repartió en dos departamentos nuevos: el de Cine, Audio y Video y el de Documentos 
Fotográficos, activos hasta hoy. La observación sobre el origen de la clasificación y las categorías del DDF responde a una intuición personal basada en indicios léxicos, compartida por ex funcionarios y funcionarios actuales del departamento, aunque sin elementos probatorios que puedan ofrecer certezas al respecto (entrevistas del autor con Miryam Casals, responsable del DDF en mayo de 2008 y con Emilia Assali, responsable del DDF en octubre de 2016).

3. Tras la consulta del Índice Temático, del Onomástico o de alguno de los índices y catálogos menores, el usuario podrá reconocer el lugar más apropiado del fichero para iniciar su búsqueda. Allí encontrará las fichas correspondientes, con una breve descripción de las respectivas fotos y los datos de ubicación (el número de caja y el de inventario), con los cuales podrá completar la búsqueda en las carpetas informáticas -cuya numeración coincide con la de las viejas cajas- que guardan copias digitales de las fotografías. La división de las cajas o carpetas no refleja la de los índices, o sea que es probable que el usuario deba revisar más de una carpeta para consultar fotografías de un mismo asunto, acontecimiento o personaje.

4. En el proceso de cambios, "aborígenes" se conservó, con sus subtemas internos, y otras categorías, como "hombres de campo", fueron abandonadas.

5. Los pies de foto son extractos de las fichas o de las inscripciones en los dorsos de las fotografías

6. Entrevista con Emilia Assali, responsable del DDF en octubre de 2016.

7. La vida de Raúl Grigeras quedó envuelta en numerosas historias diferentes que lo pintaron como holgazán o pícaro, víctima o ventajista pero, en todos los casos, como una suerte de último representante de la afroargentinidad. Para una reconstrucción de las "vidas paralelas" del Negro Raúl, Alberto (2016).

8. El DDF ofrece también a consulta la "Colección Witcomb" (1865-1920). Las Galerías de Arte Witcomb tuvieron sus inicios en 1878 como galería fotográfica, constituyendo un motor de la fotografía porteña de fines del siglo XIX y comienzos del XX.

9. Esta figura y la 11 son composiciones del autor, a partir de la extracción de los retratos de personas negras de sus páginas originales y su posterior reunión en una misma página cuadriculada del Álbum.

10. Cabe notar que en los últimos años la presión de organizaciones negras llevó a que, tras algunas pruebas piloto, se incluyeran preguntas sobre afrodescendencia en el censo nacional de población de 2010.

11. Utilizo "visibilización" para referirme a una puesta en agenda del tema que articula una discursividad heterogénea, en la cual tiene gran relevancia la palabra oral y escrita, y reservo “visualización" para referirme puntualmente al uso de imágenes.

\section{AUTHOR}

\section{SERGIO CAGGIANO}

Centro de Investigaciones Sociales - Consejo Nacional de Investigaciones Científicas y Técnicas /

Instituto de Desarrollo Económico y Social

Correo electrónico: sergio.caggiano@gmail.com 